\title{
Caracterização imuno-histoquímica das alterações encefálicas em bovinos com hepatopatia tóxica por Senecio sp. $^{1}$
}

\author{
Angelica T.B. Wouters ${ }^{2 *}$, Fabiana M. Boabaid², Gabriela Fredo ${ }^{2}$, Flademir Wouters ${ }^{2}$ \\ e David Driemeier ${ }^{2}$
}

\begin{abstract}
Wouters A.T.B., Boabaid F.M., Fredo, G., Wouters F. \& Driemeier D. 2013. [Immunohistochemical characterization of bovine brain lesions caused by Senecio sp. ingestion.] Caracterização imuno-histoquímica das alterações encefálicas em bovinos com hepatopatia tóxica causada por Senecio sp. Pesquisa Veterinária Brasileira 33(11):13251331. Setor de Patologia Veterinária, Faculdade de Veterinária, Universidade Federal do Rio Grande do Sul, Av. Bento Gonçalves 9090, Bairro Agronomia, Porto Alegre, RS 91540-000, Brazil. E-mail: angelicawouters@yahoo.com.br

Senecio spp. poisoning is an important cause of illness and death of cattle in Rio Grande do Sul, Brazil, and is often manifested by neurologic clinical signs and histological brain changes. Histological evaluation was performed on liver and brain samples of ten cattle naturally poisoned by Senecio sp. Samples of cerebrum, brainstem and cerebellum were stained with periodic acid-Schiff (PAS), and immunohistochemistry was carried out, employing anti-fibrillary acidic protein (GFAP), anti-S100 protein and anti-vimentin antibodies. The histological finding in the brain included mild to severe vacuolation in the white matter and the junction of gray and white matter, characterized as spongy degeneration. Histochemical and immunohistochemical staining revealed no significant findings compared with the brains of eleven adult cattle without liver and/or brain changes used as controls.
\end{abstract}

INDEX TERMS: Poisonous plants, Senecio spp., hepatic encephalopathy, status spongiosus, GFAP, S100, vimentin, plant poisoning, cattle.

RESUMO.- Intoxicação por Senecio spp. é causa importante de doença e morte em bovinos no Rio Grande do Sul e frequentemente cursa com manifestações clínicas neurológicas e alterações histológicas encefálicas. Foi efetuada avaliação histológica em fígado e encéfalo de dez bovinos naturalmente intoxicados por Senecio sp. e foram realizadas as técnicas de histoquímica de ácido periódico de Schiff e de imuno-histoquímica, com emprego dos anticorpos anti-proteína fibrilar ácida (GFAP), anti-proteína S100 e anti-vimentina em amostras de telencéfalo, tronco encefálico e cerebelo. Na histologia do SNC observou-se vacuolização discreta a acentuada em substância branca e/ou junção entre substância branca e cinzenta, caracterizada como degeneração esponjosa. Na avaliação histoquímica e imuno-his-

\footnotetext{
${ }^{1}$ Recebido em 18 de setembro de 2013.

Aceito para publicação em 9 de outubro de 2013.

Parte da Tese de Doutorado do primeiro autor.

${ }^{2}$ Departamento de Patologia Clínica Veterinária, Faculdade de Veterinária, Universidade Federal do Rio Grande do Sul (UFRGS), Av. Bento Gonçalves 9090, Porto Alegre, RS 95320-000, Brasil. *Autor para correspondência: angelicawouters@yahoo.com.br
}

toquímica não houve diferenças significativas em relação aos achados em encéfalo de onze bovinos controle, adultos, sem alterações hepáticas e/ou encefálicas, avaliados pelas mesmas técnicas.

TERMOS DE INDEXAÇÃO: Plantas tóxicas, Senecio spp., encefalopatia hepática, degeneração esponjosa, GFAP, S100, vimentina, intoxicação por plantas, bovinos.

\section{INTRODUÇÃO}

Senecio spp., importantes plantas tóxicas da Região Sul do Brasil, têm sido referidas como as principais dentre todas as causas de morte em bovinos nas regiões central (Rissi et al. 2007, Lucena et al. 2010) e sul (Karam et al. 2004, Schild et al. 2008) do Rio Grande do Sul e foram responsabilizadas por, aproximadamente, $50 \%$ das mortes de bovinos atribuídas à intoxicação por plantas no Rio Grande do Sul (RS), no período de 1978 a 1998 (Riet-Correa et al. 2009). Além dos prejuízos na bovinocultura, há registros de mortalidade em equinos (Gava \& Barros 1997), ovinos (Ilha et al. 2001) e búfalos (Corrêa et al. 2008) intoxicados pela planta.

Senecio sp. contém alcaloides pirrolizidínicos (AP), os 
quais estão entre as principais toxinas para bovinos em todo o mundo. Os AP ocorrem nas plantas sob duas formas; alcaloides propriamente ditos e alcaloides N-óxidos. Estes apresentam um átomo de oxigênio ligado ao anel da molécula; não são tóxicos e, quando absorvidos, são facilmente eliminados via urina. No entanto, a forma N-óxido pode ser biotransformada no intestino, contribuindo para a toxidez da planta. No fígado os AP são transformados em metabólitos pirrólicos, quimicamente muito reativos. Esses metabólitos podem causar a morte dos hepatócitos ou impedir sua mitose, de forma que continuam a aumentar de volume, com megalocitose resultante e pode também haver dano vascular. Os AP induzem lesão hepática crônica, com fibrose marcada (McKenzie 2012).

A toxidez das plantas que contém AP é variável. Os níveis de AP nessas plantas podem alterar ano a ano e têm relação com vários fatores, como época do ano, estágio de crescimento da planta, tipo de solo e sua fertilidade. Senecio brasiliensis, uma das causas mais frequentes da intoxicação por AP em bovinos no sul do Brasil, é também a espécie que apresenta as concentrações mais elevadas de AP (Karam et al 2004, Riet-Correa et al. 2009). S. brasiliensis e S. oxyphyllus são descritos como causa de surtos de intoxicação em bovinos (Barros et al. 1987, Barros et al. 1992) e equinos (Gava \& Barros 1997) na Região Central do RS e $S$. brasiliensis como causa de intoxicação em búfalos (Correa et al. 2008). Outras espécies de senécio nativas do RS, incluindo S. selloi, S. heterotrichius e S. leptolobus são também descritas como causa de intoxicação em bovinos (Karam et al. 2004). Mais recentemente, outra espécie; S. madagascariensis, foi identificada como causa de morte em bovinos. A espécie não é nativa do Brasil mas tem se alastrado no sul do País e induz lesões hepáticas idênticas às causadas por S. brasiliensis (Cruz et al. 2010).

As plantas que contêm quantidades significativas de AP geralmente não são muito palatáveis e a ingestão ocorre em situações que a favorecem, como escassez de forragem e contaminação de forragens colhidas e conservadas, como feno ou silagem, por plantas com AP (Barros et al. 2007, McKenzie 2012). A ingestão de Senecio spp. por bovinos na Região Sul do Brasil ocorre principalmente no inverno, período em que a planta se encontra em fase de brotação e apresenta maior concentração de AP, fatores que, muitas vezes, coincidem com escassez de forragem (Riet-Correa et al. 2009). Surtos de intoxicação têm sido registrados após seca prolongada (Driemeier et al. 1991, Grecco et al. 2011).

Outro fator importante é o efeito acumulativo dos AP. Assim, a ingestão pode ocorrer por meses a anos, até que haja danos hepáticos suficientemente graves para a manifestação de doença, geralmente irreversível e fatal. Animais que não adoeceram num período de ingestão de AP podem adoecer e morrer posteriormente, ao voltarem para pastagens infestadas. Em bovinos pode ocorrer doença e morte até dezoito meses após a ingestão de AP em dose única (McKenzie 2012).

No sul do Brasil, casos clínicos da intoxicação são observados, principalmente, na primavera (Barros et al. 1987, Barros et al. 1992, Karam et al. 2004, Riet-Correa et al. 2009), mas casos e até surtos podem ocorrer também em outros períodos do ano, relacionados à manifestação tardia da doença (Karam et al. 2004, Riet-Correa et al. 2009), ou mesmo quando a ingestão do senécio está atrelada ao fornecimento de forragem conservada contaminada (Barros et al. 2007). Bovinos de diferentes idades podem ser afetados, no entanto, a doença é mais comumente observada em animais adultos (Rissi et al. 2007, Riet-Correa et al. 2009), com mais de três anos de idade (Karam et al. 2004), embora Grecco et al. (2011) tenham também observado surtos de intoxicação em bovinos mais jovens.

As manifestações clínicas mais frequentes são anorexia, apatia, pelos arrepiados, tenesmo, este muitas vezes seguido por prolapso retal; afastamento do rebanho, perda de peso, ascite, distúrbios digestivos e neurológicos. Dois cursos clínicos podem ser identificados; um prolongado, caracterizado por perda de peso progressiva até a morte, que geralmente ocorre em várias semanas ou meses; ou um curso agudo ou subagudo, com morte em poucos dias (Barros et al. 1992).

Achados de necropsia incluem fígado reduzido de volume e bronzeado, com nódulos de 0,2 a 0,6cm de diâmetro, aleatoriamente distribuídos pelo parênquima hepático, além de vesícula biliar distendida, hidropericárdio, ascite e edema de mesentério (Cruz et al. 2010). Podem estar presentes, também, edema e hiperplasia adenomatosa da mucosa da vesícula biliar (Barros et al. 1992). Variações podem ser observadas nas alterações macroscópicas do fígado, que foram classificadas por Grecco et al. (2010) em padrões morfológicos distintos, relacionados à diversidade em nodulações e coloração.

Encefalopatia hepática $(\mathrm{EH})$ é relacionada a lesões hepáticas crônicas em bovinos, no Brasil devidas, especialmente, à ingestão de Senecio spp. (Méndez et al. 1987, Barros et al. 1992, Tokarnia et al. 2012), com descrição de alteração ou degeneração esponjosa, conhecida como "status spongiosus", no sistema nervoso central (SNC). Essa alteração é caracterizada por microcavitações, mais evidentes em tratos mielinizados da substância branca encefálica e na interface entre substância branca e cinzenta do córtex telencefálico (Barros 2010), bem como em cápsula interna, tálamo e colículos e, às vezes, na substância cinzenta (Riet-Correa et al. 2009).

Degeneração esponjosa é descrita relacionada a várias causas de hepatopatia difusa em diferentes espécies animais por Hooper (1975), com formação de vacúolos, principalmente ao longo de determinados tratos axonais de substância branca e contíguos à substância cinzenta. A distribuição regular dos vacúolos nas mesmas áreas do SNC em um grande número de animais com EH é sugerida pelo mesmo autor como uma entidade específica relacionada à hiperamonemia. Cho \& Leipold (1977) induziram, por infusão intravenosa de acetato de amônio, vacuolização acentuada da substância branca no encéfalo de bezerros e, menos intensa, na substância cinzenta do encéfalo e da medula espinhal.

O objetivo desse trabalho é descrever os achados histológicos em fígado e, principalmente, em encéfalo de bovinos naturalmente intoxicados por Senecio sp. e sua caracterização imuno-histoquímica em telencéfalo, tronco encefálico 
e cerebelo, usando os anticorpos anti-GFAP, anti-proteína S100 (anti-S100) e anti-vimentina.

\section{MATERIAL E MÉTODOS}

Dez casos de bovinos com diagnóstico de intoxicação espontânea por Senecio sp., para os quais havia amostras de telencéfalo, tronco encefálico, cerebelo e fígado emblocadas em parafina foram selecionados do arquivo do Setor de Patologia Veterinária da Universidade Federal do Rio Grande do Sul (SPV-UFRGS). Foram realizados cortes de $3 \mu \mathrm{m}$ de espessura das amostras de fígado, telencéfalo, tronco encefálico e cerebelo, corados por hematoxilina e eosina e avaliados na histologia. Dados disponíveis acerca do histórico, das manifestações clínicas e dos achados de necropsia foram recuperados. Foi realizada a técnica histoquímica de ácido periódico de Shiff (PAS) nas amostras de telencéfalo, tronco encefálico e cerebelo, em cortes de mesma espessura. Cortes das mesmas áreas selecionadas do SNC foram submetidos à técnica de IHQ, pelo método da estreptavidina-biotina ligada à peroxidase para os anticorpos anti-GFAP e anti-S100 e pelo método da estreptavidina-biotina ligada à fosfatase para o anticorpo anti-vimentina (Quadro 1).

Como controle negativo foram avaliadas as mesmas áreas do encéfalo de 11 bovinos da rotina de diagnóstico do SPV. Os casos selecionados para esse fim eram bovinos adultos, com diferentes causas de morte, porém sem alterações clínicas e/ou lesões hepáticas nem encefálicas, com realização das técnicas de histoquímica de PAS e de IHQ usando os mesmos anticorpos.

\section{Quadro 1. Recuperações antigênicas, diluições e origem dos anticorpos primários utilizados na técnica de imuno-histoquímica}

\begin{tabular}{|c|c|c|c|c|}
\hline $\begin{array}{l}\text { Anticorpo } \\
\text { primário }\end{array}$ & $\begin{array}{l}\text { Especificações } \\
\text { do anticorpo }\end{array}$ & $\begin{array}{c}\text { Recuperação } \\
\text { antigênica* }\end{array}$ & $\begin{array}{l}\text { Diluição do } \\
\text { anticorpo }\end{array}$ & $\begin{array}{l}\text { Referência } \\
\text { comercial }\end{array}$ \\
\hline Anti-GFAP & $\begin{array}{l}\text { Policlonal } \\
\text { coelho }\end{array}$ & $\begin{array}{l}\text { TRIS-EDTA pH 9.0, } \\
96^{\circ} \mathrm{C}, 40 \mathrm{~min}\end{array}$ & $0, \quad 1: 500$ & Dako \\
\hline Anti-S100 & $\begin{array}{l}\text { Policlonal } \\
\text { coelho }\end{array}$ & $\begin{array}{l}\text { Citrato } \mathrm{pH} 6.0 \text {, } \\
96^{\circ} \mathrm{C}, 40 \mathrm{~min}\end{array}$ & $1: 200$ & Dako \\
\hline Anti-vimentina & $\begin{array}{c}\text { Clone V9 } \\
\text { camundongo }\end{array}$ & $\begin{array}{c}\text { Citrato } \mathrm{pH} 6.0 \\
125^{\circ} \mathrm{C}, 3 \mathrm{~min}\end{array}$ & $1: 200$ & Zymed \\
\hline
\end{tabular}

* Obtida em panela de pressão.

\section{RESULTADOS}

Todos os casos do estudo são de intoxicação espontânea por Senecio sp. Dados de histórico, achados clínicos e de necropsia são apresentados no Quadro 2.

$\mathrm{Na}$ avaliação histológica dos fígados foram observados fibrose, proliferação de ductos biliares, nódulos de regeneração, megalocitose e degeneração vacuolar de hepatócitos (Fig.1) em todos os casos, porém com variações entre eles, principalmente em intensidade (Quadro 3).

Nas amostras de encéfalo verificaram-se, histologicamente, vacuolização discreta a acentuada no neurópilo em todos os casos, alterações astrocíticas e edema perivascular (Quadro 4). No telencéfalo havia vacuolização difusa do neurópilo na junção entre substância cinzenta e branca (Bovinos 1, 5, 6, 7, 8, 9 e 10), focal na substância branca subcortical (Bovino 2) e em área mais profunda do córtex (Bovinos 5, 6 e 9). As alterações astrocíticas no telencéfalo foram discretas e caracterizadas por núcleo discretamente tumefeito (Bovinos 7 e 10) a vesicular (Bovinos 7 e 9), nas porções profundas do córtex telencefálico (Bovinos 9 e 10) e/ou na substância branca subcortical (Bovino 10). No tronco encefálico havia vacuolização com formação de vacúolos de formas e tamanhos irregulares (Fig.2) atingindo as substâncias cinzenta e branca (Bovinos 7 e 10) ou a substância branca (Bovino 6). Alterações semelhantes às encontradas no telencéfalo foram observadas nos astrócitos do tronco encefálico em dois casos (Bovinos 7 e 10). No cerebelo havia vacuolização na substância branca, especialmente em pedúnculos cerebelares e fólios (Bovinos 5, 6 e 10), com distribuição multifocal a coalescente (Bovino 6) ou difusa (Bovinos 5 e 10) e foi também observada tumefação nuclear em astrócitos da substância branca dos fólios, bem como em astrócitos de Bergmann (Bovinos 6 e 8).

Na técnica histoquímica de PAS não havia alterações significativas nos cortes de telencéfalo, tronco encefálico e cerebelo dos casos estudados, bem como nos cortes de encéfalo dos bovinos controle.

Para as técnicas de IHQ empregadas, a aplicação do anticorpo anti-GFAP resultou na imunomarcação dos processos astrocíticos, semelhante à marcação observada no encéfalo dos bovinos controle, e houve evidenciação da tumefação de núcleos astrocíticos (Fig.3 e 4). No emprego do anticorpo anti-S100 houve evidente imunomarcação do núcleo e do citoplasma de astrócitos em substância cinzenta e branca de telencéfalo, tronco encefálico e cerebelo, semelhante à marcação observada em animais controle. $\mathrm{Na}$ IHQ anti-vimentina houve forte imunomarcação em paredes vasculares (Fig.5), sem diferença em relação àquela observada nos cortes de encéfalo dos animais controle.

\section{DISCUSSÃO E CONCLUSÕES}

A análise histológica do fígado revelou fibrose, proliferação de ductos biliares e megalocitose, alterações consideradas características da intoxicação por AP (Barros et al. 1992, Driemeier \& Barros 1992, Barros et al. 2007), com variações entre os casos, principalmente em intensidade. Grecco et al. (2010) também encontraram variação em intensidade e distribuição das alterações e não observaram relação dessas variações com a idade dos animais, tempo de evolução da intoxicação e sinais clínicos, no entanto, sugerem influência das condições climáticas no aumento da frequência da doença, relacionando oferta de forragem versus senécio para os animais.

Da região do tronco encefálico foi examinado óbex ou mesencéfalo, com disponibilidade de óbex em maior número de casos (6/10 bovinos), relacionada ao fato desses animais serem submetidos à investigação de lesões de encefalopatia espongiforme bovina e o óbex constituir a região encefálica de eleição para confirmação diagnóstica dessa enfermidade, no entanto, as lesões decorrentes da intoxicação foram mais acentuadas no mesencéfalo, avaliado em 4/10 casos, com vacuolização moderada e acentuada, achados semelhantes aos descritos por Méndez et al. (1987), Driemeier \& Barros (1992), Sanches et al. (2000) e Santos et al. (2008) em bovinos e também por Ilha et al. (2001) em ovinos.

As técnicas de histoquímica de PAS e de IHQ anti-vi- 
Quadro 2. Dados de histórico, achados clínicos e de necropsia de bovinos com intoxicação espontânea por Senecio sp. selecionados para o estudo de caracterização imuno-histoquímica das alterações encefálicas

\begin{tabular}{|c|c|c|c|c|c|}
\hline Bovino & $\begin{array}{l}\text { Procedência } \\
\text { (Raça) }\end{array}$ & Sexo & $\begin{array}{l}\text { Idade } \\
\text { (anos) }\end{array}$ & Histórico e achados clínicos & Achados de necropsia \\
\hline 1 & $\begin{array}{l}\text { S. Jerônimo/RS } \\
\text { (Aberdeen Angus) }\end{array}$ & $\mathrm{F}$ & 5 & $\begin{array}{l}\text { Diarreia esverdeada, desidratação, agressivi- } \\
\text { dade, queda e morte quando movimentado. } \\
\text { Morte na primavera. }\end{array}$ & $\begin{array}{l}\text { Desidratação acentuada, ascite, edema acentuado em me- } \\
\text { sentério e abomaso. Fígado esbranquiçado, firme e com } \\
\text { nódulos vermelho-pálidos aprox. } 0,5 \mathrm{~cm} \emptyset \text {. }\end{array}$ \\
\hline 2 & (Holandesa) * & $\mathrm{F}$ & Adult & $\begin{array}{l}\text { Animal prenhe, apresentou queda e decúbito } \\
\text { permanente. Morte em final de outono. }\end{array}$ & $\begin{array}{l}\text { Ascite, edema e hemorragia em serosas, edema em muco- } \\
\text { sa abomasal, conteúdo ressecado em cólon espiral. Fíga- } \\
\text { do firme, com áreas claras. }\end{array}$ \\
\hline 3 & $\begin{array}{l}\text { Caçapava do } \\
\text { Sul/RS } \\
\text { (Brangus) }\end{array}$ & M & 2 & $\begin{array}{l}\text { Morte de } 21 / 70 \text { machos nascidos na proprie- } \\
\text { dade, há um ano em potreiro com Senecio sp.; } \\
\text { mortes na primavera. Tenesmo, apatia, sinais } \\
\text { neurológicos incluindo andar a esmo. }\end{array}$ & $\begin{array}{l}\text { Desidratação, edema acentuado em mesentério e aboma- } \\
\text { so, prolapso retal. Fígado pálido, diminuído e firme. }\end{array}$ \\
\hline 4 & $\begin{array}{l}\text { S. Jerônimo/RS } \\
\text { (Aberdeen Angus) }\end{array}$ & $\mathrm{F}$ & 6 & $\begin{array}{l}500 \text { bovinos/700ha campo nativo com sené- } \\
\text { cio, predomínio } S \text {. madagascariensis. Agressi- } \\
\text { vidade. Mortes no verão, em média } 10 \text { bovi- } \\
\text { nos/ ano. }\end{array}$ & $\begin{array}{l}\text { Bom estado corporal, mucosas pálidas, prolapso retal, as- } \\
\text { cite, hidrotórax e hidropericárdio, hemorragias em omen- } \\
\text { to e serosa omasal, edema acentuado em parede aboma- } \\
\text { sal, conteúdo intestinal liquefeito. Fígado pálido, firme, } \\
\text { reduzido, edema em parede de vesícula biliar, repleta. }\end{array}$ \\
\hline 5 & $\begin{array}{c}\text { Passinho } \\
\text { Triunfo/RS (SRD) }\end{array}$ & $\mathrm{F}$ & 1 e meio & $\begin{array}{l}\text { Dificuldade locomoção, afastamento do reba- } \\
\text { nho, tenesmo, fezes ressecadas, febre. Morte } \\
\text { no outono. }\end{array}$ & $\begin{array}{l}\text { Regular estado corporal, sangue mais aquoso, hemorra- } \\
\text { gias subepicárdicas, conteúdo retal ressecado. Fígado di- } \\
\text { minuído, pálido e firme. }\end{array}$ \\
\hline 6 & $\begin{array}{l}\text { Cristal/RS } \\
\text { (Angus) }\end{array}$ & $\mathrm{F}$ & 2 & $\begin{array}{l}\text { Morte } 24 / 99 \text { bovinos em campo nativo, su- } \\
\text { perlotação. Emagrecimento, distensão abdo- } \\
\text { minal, apatia, tenesmo e prolapso retal, diar- } \\
\text { reia/constipação. Mortes na primavera. }\end{array}$ & $\begin{array}{l}\text { Mau estado corporal. Linfonodos hepáticos e mesenté- } \\
\text { ricos suculentos. Fígado reduzido, pálido, firme, nodula- } \\
\text { ções amareladas } 0,1 \text { a } 0,3 \mathrm{~cm} \emptyset \text {. Vesícula biliar com pare- } \\
\text { de espessa e formações polipoides de } 0,2 \text { a } 1 \mathrm{~cm} \emptyset \text {. }\end{array}$ \\
\hline 7 & $\begin{array}{l}\text { Pouso Novo/RS } \\
\text { (SRD) }\end{array}$ & $\mathrm{F}$ & NI & $\begin{array}{l}\text { Aprox. } 50 \text { bovinos } / 30 \text { ha, pasto com } S \text {. bra- } \\
\text { siliensis, silagem e ração no cocho. Terceira } \\
\text { morte (primavera) em } 30 \text { dias, diarreia, te- } \\
\text { nesmo, fezes escuras e aumento tempo coa- } \\
\text { gulação }\end{array}$ & $\begin{array}{l}\text { Péssimo estado corporal, mucosas pálidas, ascite, edema } \\
\text { de mesentério. Fígado reduzido, superfície irregular, fir- } \\
\text { me, com pontos brancacentos e nódulos de } 0,1 \text { a } 0,3 \mathrm{~cm} \emptyset \text {. }\end{array}$ \\
\hline 9 & $\begin{array}{l}\text { Dois Irmãos/RS } \\
\text { (Cruza Nelore) }\end{array}$ & $\mathrm{F}$ & 2 e meio & $\begin{array}{l}\text { Anorexia, incoordenação, diarreia e incapaci- } \\
\text { dade de levantar-se. Morte no início de verão. }\end{array}$ & $\begin{array}{l}\text { Regular estado corporal, ascite moderada. Fígado redu- } \\
\text { zido, firme e vermelho-escuro, anastomoses portossistê- } \\
\text { micas em vasos mesentéricos. Formações polipoides em } \\
\text { vesícula biliar. }\end{array}$ \\
\hline 10 & $\begin{array}{l}\text { Cachoeira do } \\
\text { Sul/RS (SRD) }\end{array}$ & M & 2 e meio & $\begin{array}{l}\text { Quatro mortes em 2011, em } 2012 \text { cinco ani- } \\
\text { mais/60, mais um doente. Diarreia escura e } \\
\text { emagrecimento por aprox. } 10 \text { dias. Andar } \\
\text { cambaleante, afastamento do lote, anorexia, } \\
\text { polidipsia. Decúbito esternal. Mortes na pri- } \\
\text { mavera. }\end{array}$ & $\begin{array}{l}\text { Regular estado corporal, prolapso retal, ascite e hidrotó- } \\
\text { rax, edema acentuado em mesocólon, parede abomaso e } \\
\text { vesícula biliar. Petéquias em serosa intestinal. Fígado fir- } \\
\text { me, fina trama brancacenta ao corte, formações polipoi- } \\
\text { des em vesícula biliar, anastomoses portossistêmicas em } \\
\text { vasos mesentéricos. }\end{array}$ \\
\hline
\end{tabular}

F = fêmea; $M$ = macho; * Dados sobre procedência não encontrados; $\mathrm{SRD}$ = sem raça definida.

mentina, empregadas para a avaliação de paredes vasculares e de material extravasado, apresentaram resultados similares aos encontrados em animais controle, indicando que a vacuolização encefálica não decorre de alterações vasculares nos casos de intoxicação crônica por Senecio sp. Hooper (1975) também não obteve achados relevantes na coloração de PAS aplicada em encéfalos de diferentes espécies animais com EH. Na pesquisa de Cho \& Leipold (1977) nenhum material foi evidenciado nesses vacúolos em HE, nem em colorações especiais; não foi observada relação das cavitações com estruturas vasculares e também não havia alteração em espaços perivasculares.

Os exames histológico e de IHQ com uso dos anticorpos anti-GFAP e anti-S100, revelaram alterações astrocíticas discretas em 5 dos 10 casos avaliados, apesar de haver, em todos eles, alterações hepáticas acentuadas. Em casos de intoxicação de bovinos por Cestrum intermedium, planta de ação hepatotóxica aguda que cursa com sinais clínicos de 


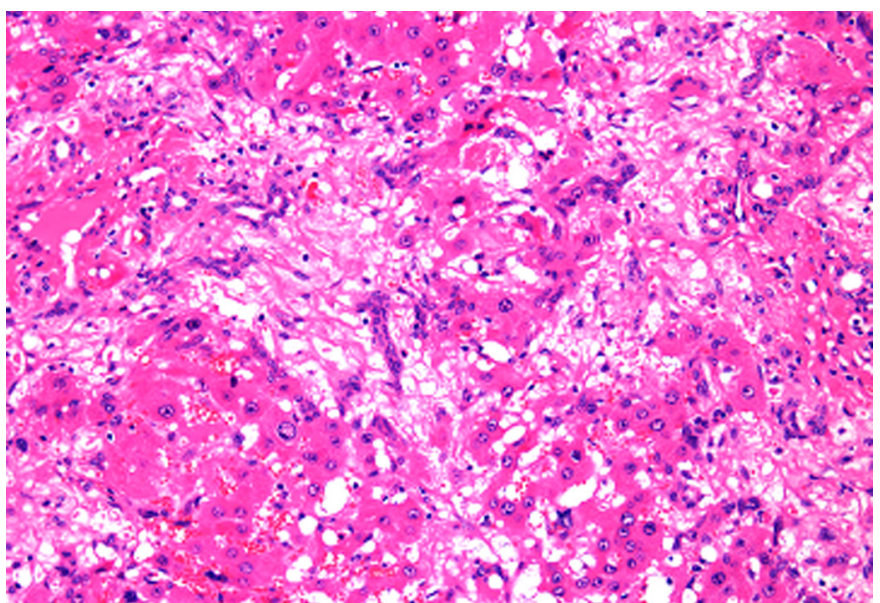

Fig.1. Aspecto histológico do fígado de bovino (Bov.3) intoxicado por Senecio sp., evidenciando fibrose, proliferação de ductos biliares, nódulos de regeneração, megalocitose e degeneração hepatocelular. HE, obj.20x.

\section{Quadro 3. Alterações histológicas em fígado de bovinos com intoxicação espontânea por Senecio sp.}

Bovino Fibrose Proliferação Nódulos Megalocitose Degeneração ductos regeneração vacuolar de

biliares hepatócitos

\begin{tabular}{lccccc}
\hline 1 & +++ & ++ & ++ & + & - \\
$2^{*}$ & ++ & + & - & + & ++ \\
3 & ++ & +++ & + & ++ & - \\
4 & +++ & ++ & + & ++ & - \\
$5^{* *}$ & +++ & +++ & + & ++ & - \\
$6^{* *}$ & +++ & +++ & +++ & + & + \\
7 & +++ & +++ & +++ & ++ & - \\
8 & +++ & +++ & + & +++ & - \\
9 & ++ & +++ & + & +++ & - \\
10 & +++ & +++ & +++ & ++ & +
\end{tabular}

* Havia também congestão acentuada; ${ }^{* *}$ colestase discreta e discreto infiltrado mononuclear; - ausente; + discreto; ++ moderado; +++ acentuado.

EH, há achados histológicos encefálicos com alterações astrocíticas evidentes em cérebro e cerebelo, caracterizadas por tumefação celular com citoplasma amplo e eosinofílico, núcleo picnótico, ora excêntrico, mais evidentes em substância branca (Wouters et al. 2013). Esses dados sugerem que as alterações astrocíticas são precoces na EH e que, nos casos de intoxicação por Senecio sp., que são caracterizados

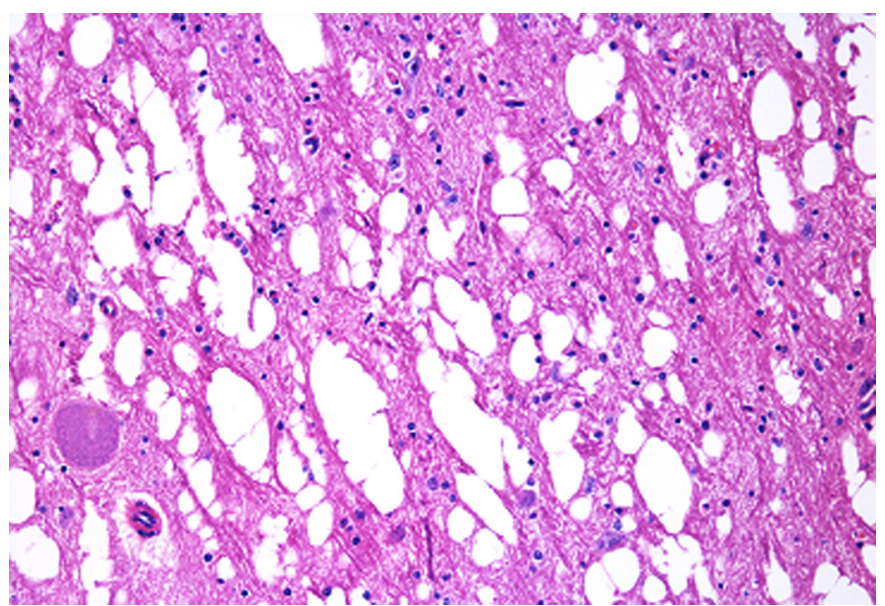

Fig.2. Degeneração esponjosa em tronco encefálico de bovino (Bov.10) intoxicado por Senecio sp. HE, obj.20x.

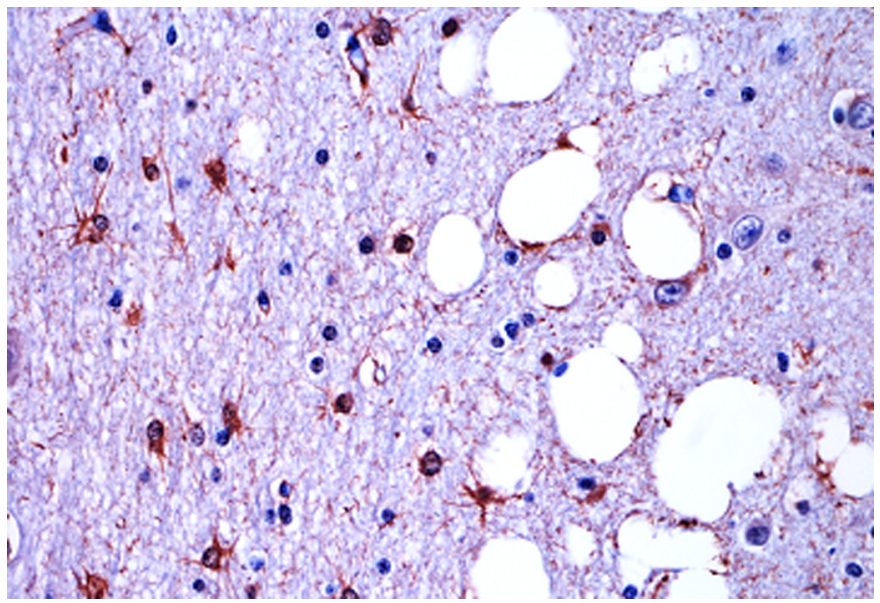

Fig.3. Junção entre córtex e substância branca em telencéfalo de bovino intoxicado por Senecio sp. (Bov.6), com degeneração esponjosa e ocasionais astrócitos com núcleo discretamente tumefeito na substância cinzenta. Imunomarcação anti-S100, método da Estreptavidina-biotina-peroxidase, cromógeno Vector Nova Red, obj.40x.

por evolução crônica - a maioria dos casos; ou subaguda (Driemeier \& Barros 1992), a patogenia das alterações encefálicas seja diferente.

Quadro 4. Alterações histológicas em encéfalo de bovinos com intoxicação espontânea por Senecio sp.

\begin{tabular}{|c|c|c|c|c|c|c|c|c|c|}
\hline \multirow[t]{2}{*}{ Bovino } & \multicolumn{3}{|c|}{ Vacuolização } & \multicolumn{3}{|c|}{ Alterações astrocíticas } & \multicolumn{3}{|c|}{ Edema perivascular } \\
\hline & $\begin{array}{l}\text { Telen- } \\
\text { céfalo }\end{array}$ & Tronco* & Cerebelo & $\begin{array}{c}\text { Telen } \\
\text {-céfalo }\end{array}$ & Tronco & Cerebelo & $\begin{array}{l}\text { Telen- } \\
\text { céfalo }\end{array}$ & Tronco & Cerebelo \\
\hline 1 & ++ & + & + & - & - & - & + & - & - \\
\hline 2 & + & - & - & - & - & - & + & - & - \\
\hline 3 & + & + & - & - & - & - & + & - & - \\
\hline 4 & - & + & - & - & - & - & - & - & - \\
\hline 5 & +++ & +++ & + & - & - & - & - & - & - \\
\hline 6 & ++ & +++ & +++ & - & - & + & + & - & + \\
\hline 7 & ++ & + & - & + & + & - & - & - & - \\
\hline 8 & + & ++ & - & - & & + & - & - & - \\
\hline 9 & +++ & ++ & - & + & - & - & + & - & - \\
\hline 10 & ++ & +++ & + & + & + & - & - & - & - \\
\hline
\end{tabular}

* Tronco $=$ tronco encefálico. 


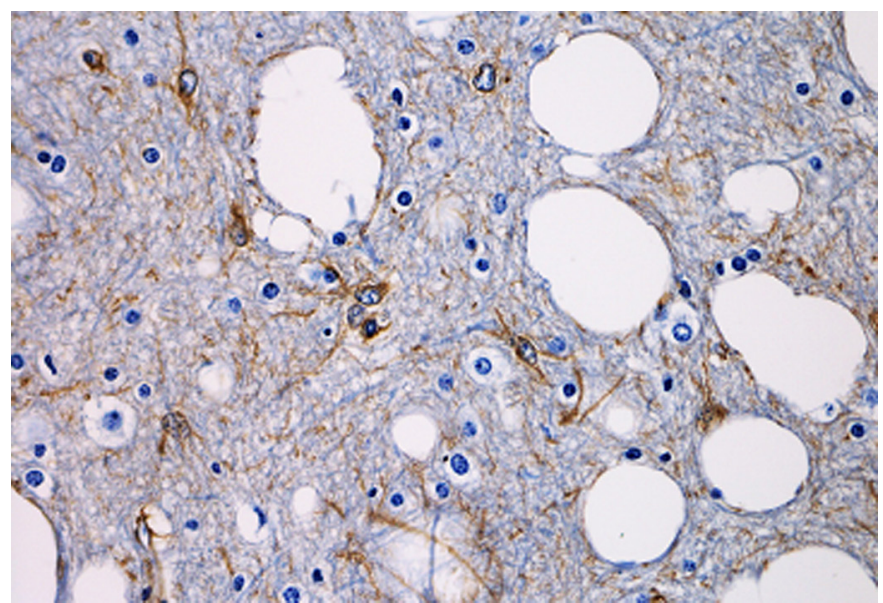

Fig.4. Degeneração esponjosa na junção entre substâncias cinzenta e branca em telencéfalo de bovino intoxicado por Senecio sp. (Bov.5). Imunomarcação anti-GFAP, Método da Estreptavidina-biotina-peroxidase. Cromógeno DAB, obj.40x.

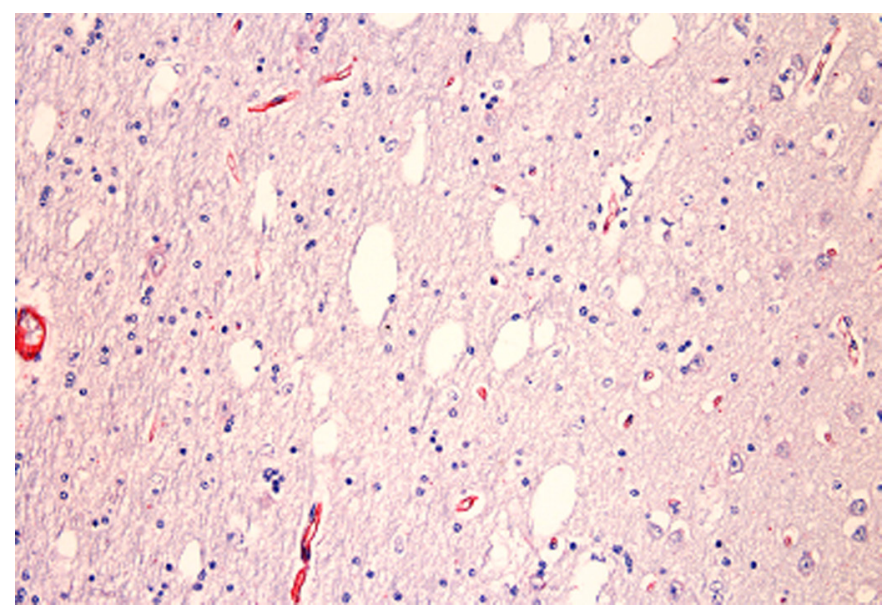

Fig.5. Junção entre córtex e substância branca do telencéfalo de bovino intoxicado por Senecio sp. (Bov.10) com marcação de paredes de vasos sanguíneos em vermelho. Imunomarcação anti-vimentina, método da estreptavidina ligada à fosfatase alcalina, Cromógeno Permanent Red, obj.20x.

É descrito que astrócitos jovens ou que sofreram agressão podem sintetizar vimentina (Orsini et al. 2007). Nos encéfalos avaliados por IHQ usando anticorpo anti-vimentina não houve imunomarcação em astrócitos.

A degeneração esponjosa tem sido atribuída a edema intramielínico (Sanches et al. 2000, Santos et al. 2008, Riet-Correa et al. 2009, Lucena et al. 2010), causando separação e vacuolização de bainhas de mielina (Summers et al. 1995, Barros 2010).

As bainhas de mielina, constituídas por arranjos concêntricos de processos oligodendrogliais compactados ao redor de axônios, são dispostas em segmentos espaçados pelos nodos de Ranvier. A região nodal, envolta por processos astrocíticos e oligodendrogliais e a compactação desses processos determinam a ocorrência de duas linhas distintas na bainha; a linha densa principal e a linha interperiódica (Graça et al. 2010). Estes autores relacionam a degeneração esponjosa a edema nas bainhas de mielina, com separação das lamelas na linha interperiódica, e a edema astrocitário.

Em estudos de microscopia eletrônica, descritos por Cho \& Leipold (1977), as alterações identificadas no exame histológico como degeneração esponjosa revelaram ser grandes espaços vazios nas bainhas de mielina, dispostos entre as linhas densas das membranas mielínicas e separação do espiral da mielina na lamela intraperiódica, com distensão de espaços extracelulares e tumefação mitocondrial e, quando de vacúolos múltiplos dentro de uma mesma lamela de mielina, correspondem a ruptura de membranas de mielina. Rissi et al. (2010) também mencionam demonstração de edema intramielínico pela microscopia eletrônica em casos com degeneração esponjosa relacionada a insuficiência hepática crônica decorrente de intoxicação por AP.

Por outro lado, os estudos em microscopia eletrônica descritos por Cho \& Leipold (1977) revelaram alterações escassas em astrócitos e seus processos, ausentes em células da glia, vasos sanguíneos e membranas basais.

Os métodos de histoquímica de PAS, e de IHQ com emprego dos anticorpos anti-GFAP, anti-S100 e anti-vimentina demonstraram, no presente estudo, não haver alterações significativas em estruturas vasculares e em astrócitos encefálicos nos casos de intoxicação de bovinos por Senecio sp., o que corrobora com a patogenia anteriormente proposta; a degeneração esponjosa, típica nessa intoxicação, é caracterizada por edema intramielínico. Esse edema é considerado resultado de alteração seletiva no sistema de transporte ativo de íons e água, dependente de energia na membrana das células, como é proposto por Cho \& Leipold (1977).

Agradecimentos. Ao Conselho Nacional de Desenvolvimento Científico e Tecnológico (CNPq).

\section{REFERÊNCIAS}

Barros C.S.L., Metzdorf L.L. \& Peixoto P.V. 1987. Ocorrência de surtos da intoxicação por Senecio brasiliensis (Compositae) em bovinos no Rio Grande do Sul. Pesq. Vet. Bras. 7:101-107.

Barros C.S.L., Driemeier D., Pilati C., Barros S.S. \& Castilhos L.M.L. 1992. Senecio spp. poisoning in cattle in southern Brazil. Vet. Human Toxicol. 34:241-246.

Barros C.S.L. 2010. Fígado, vias biliares e pâncreas exócrino, p.183-290. In: Santos R.L. \& Alessi A.C. (Eds), Patologia Veterinária. Roca, São Paulo.

Barros C.S.L., Castilhos L.M.L., Rissi D.R., Kommers G.D. \& Rech R.R. 2007. Biópsia hepática no diagnóstico da intoxicação por Senecio brasiliensis (Asteraceae) em bovinos. Pesq. Vet. Bras. 27(1):53-60.

Cho D.Y. \& Leipold H.W. 1977. Experimental spongy degeneration in calves. Acta Neuropathol. 39:115-127.

Corrêa A.M.R., Bezerra P.S.J., Pavarini S.P., Santos A.S., Sonne L., Zlotowski P., Gomes G. \& Driemeier D. 2008. Senecio brasiliensis (Asteraceae) poisoning in Murrah buffaloes in Rio Grande do Sul. Pesq. Vet. Bras. 28(3):187-189.

Cruz C.E.F., Karam F.C., Dalto A.C., Pavarini S.P., Bandarra P.M. \& Driemeier D. 2010. Fireweed (Senecio madagascariensis) poisoning in cattle. Pesq. Vet. Bras. 30(1):10-12.

Driemeier D. \& Barros C.S.L. 1992. Intoxicação experimental por Senecio oxyphyllus (Compositae) em bovinos. Pesq. Vet. Bras. 12:33-42.

Driemeier D., Barros C.S.L. \& Pilati C. 1991. Seneciose em bovinos. Hora Vet. 59:23-30.

Gava A. \& Barros C.S.L. 1997. Senecio spp. poisoning of horses in southern Brazil. Pesq. Vet. Bras. 17(1):36-40. 
Graça D.L., Alessi A.C., Ecco R. \& Viott A.M. 2010. Patologia do sistema nervoso, p.525-610. In: Santos R.L. \& Alessi A.C. (Eds), Patologia Veterinária. Roca, São Paulo.

Grecco F.B., Schild A.L., Soares M.P., Marcolongo-Pereira C., Estima-Silva P. \& Sallis E.S.V. 2010. Aspectos epidemiológicos e padrões de lesões hepáticas em 35 surtos de intoxicação por Senecio spp. em bovinos no sul do Rio Grande do Sul. Pesq. Vet. Bras. 30(5):389-397.

Grecco F.B., Schild A.L., Estima-Silva P., Marcolongo-Pereira C., Soares M.P. \& Sallis E.S.V. 2011. Possible association between precipitation and incidence of Senecio spp. poisoning in cattle in southern Brazil, p.154-157. In: Riet Correa F., Pfister J., Schild A.L. \& Wierenga T.L. (Eds), Poisoning by Plants, Mycotoxins and related Toxins. CABI, Oxfordshire, UK.

Hooper P.T. 1975. Spongy degeneration in the central nervous system of domestic animals. I. Morphology. Acta Neuropathol. 31:325-334.

Ilha M.R., Loretti A.P., Barros S.S. \& Barros C.S.L. 2001. Intoxicação espontânea por Senecio brasiliensis (Asteraceae) em ovinos no Rio Grande do Sul. Pesq. Vet. Bras. 21:123-138.

Karam F.S.C., Soares M.P., Haraguchi M., Riet-Correa F., Méndez M.C. \& Jarenkow J.A. 2004. Aspectos epidemiológicos da seneciose na região sul do Rio Grande do Sul. Pesq. Vet. Bras. 24(4):191-198.

Lucena R.B., Rissi D.R., Maia L.A., Dantas A.F.M., Flores M.A., Nobre V.M.T., Riet-Correa F. \& Barros C.S.L. 2010. Intoxicação por alcaloides pirrolizidínicos em ruminantes e equinos no Brasil. Pesq. Vet. Bras. 30(5):447452.

McKenzie R.A. 2012. Australia's Poisonous Plants, Fungi and Cyanobacteria: a guide to species of medical and veterinary importance. CSIRO Publishing, Collingwood. 950p.

Méndez M.C., Riet-Correa F. \& Schild A.L. 1987. Intoxicação por Senecio spp. em bovinos no Rio Grande do Sul. Pesq. Vet. Bras. 7:51-56.

Orsini H., Bondan E.F., Sanchez M., Lallo M.A., Maiorka P.C., Dagli M.L.Z. \& Graça D.L. 2007. Marcação imunoistoquímica da expressão astrocitária de proteína glial fibrilar ácida e de vimentina no sistema nervoso central de cães com cinomose. Arq. Neuropsiquiatr. 65:1070-1077.

Riet-Correa F., Medeiros R.M.T., Pfister J., Schild A.L. \& Dantas A.F.M. 2009. Poisonings by Plants, Mycotoxins and Related Substances in Brazilian Livestock. UFCG, Campina Grande/PB. 246p.

Rissi D.R., Pierezan F., Oliveira-Filho J.C., Lucena R.B., Carmo P.M.S. \& Barros C.S.L. 2010. Abordagem diagnóstica das principais doenças do sistema nervoso de ruminantes e equinos no Brasil. Pesq. Vet. Bras. 30(11):958-967.

Rissi D.R., Rech R.R., Pierezan F., Gabriel A.L., Trost M.E., Brum J.S., Kommers G.D. \& Barros C.S.L. 2007. Intoxicações por plantas e micotoxinas associadas a plantas em bovinos no Rio Grande do Sul: 461 casos. Pesq. Vet. Bras. 27:261-268.

Sanches A.W.D., Langohr I.M., Stigger A.L. \& Barros C.S.L. 2000. Doenças do sistema nervoso central em bovinos no Sul do Brasil. Pesq. Vet. Bras. 20(3):113-118.

Santos J.C.A., Riet-Correa F., Simões S.V.D. \& Barros C.S.L. 2008. Patogênese, sinais clínicos e patologia das doenças causadas por plantas hepatotóxicas em ruminantes e equinos no Brasil. Pesq. Vet. Bras. 28(1):1-14.

Schild A.L., Ferreira J.L.M., Ladeira S.R.L., Soares M.P., Grecco F.B., Marcolongo-Pereira C. \& Fiss L. 2008. Doenças diagnosticadas pelo Laboratório regional de Diagnóstico no ano 2007. Boletim do Laboratório Regional de Diagnóstico. Editora Universitária, UFPel, Pelotas, p.60-63.

Summers B.A., Cummings J.F. \& De Lahunta A. 1995. Veterinary Neuropathology. Mosby, St Louis. 527p.

Tokarnia C.H., Brito M.F., Barbosa J.M., Peixoto P.V. \& Döbereiner J. 2012. Plantas Tóxicas do Brasil para Animais de Produção. $2^{\underline{a}}$ ed. Helianthus, Rio de Janeiro. 566p.

Wouters A.T.B., Boabaid F.M., Watanabe T.T.N., Bandarra P.M., Correa G.L.F., Wouters F., Mafessoni R.M. \& Driemeier D. 2013. Intoxicação espontânea por Cestrum intermedium em bovinos no Sudoeste do Estado do Paraná. Pesq. Vet. Bras. 33(1):47-51. 